\title{
EFFECT OF NATURAL AND SYNTHETIC POLYMERS ON THE PROPERTIES OF CANDESARTAN CILEXETIL MATRIX TABLET PREPARED BY DRY GRANULATION
}

\author{
OMAR S SALIH*, ROAA A NIEF \\ Department of Pharmaceutics, College of Pharmacy, University of Baghdad, Iraq. Email: omarpharma2007@gmail.com
}

Received: 16 August 2016, Revised and Accepted: 31 August 2016

\section{ABSTRACT}

Objective: The objective of this study is to develop a controlled release matrix tablet of candesartan cilexetil to reduce the frequency of administration, enhance bioavailability and improve patient compliance; a once daily sustained release formulation of candesartan cilexetil is desirable.

Methods: The prepared tablets from F1 to F24 were evaluated with different evaluation parameters like weight variation, drug content, friability, hardness, thickness and swelling ability. In vitro release for all formulas were studied depends on the type and amount of each polymer, i.e. (16 mg, $32 \mathrm{mg}$ and $48 \mathrm{mg}$ ) respectively beside to the combination effect of polymers on the release of the drug from the tablet.

Results: In vitro release showed that formula 13 had the faster release $(100 \%$ after $4 \mathrm{~h})$ which contained acacia (1:1) and the lowest sustain release was showed for F7 (73\% after $8 \mathrm{~h}$ ) which contained HPMC K100M (1:1). Formula 1 was an $89 \%$ release after $8 \mathrm{~h}$ which contain eudragit RS100; F4 was a $100 \%$ release after $5 \mathrm{~h}$ which contain Na CMC, F10 was a $100 \%$ after $8 \mathrm{~h}$ which contain xanthan gum and F16 was a $100 \%$ release after $5 \mathrm{~h}$ which contain tragacanth polymer. Formula 9 had a lower release than F7 and F8 respectively. Formula 7 can be used for sustain oral drug delivery of candesartan cilexetil while Formula 13 can be used in contrary as fast release tablets for faster response.

Conclusion: Controlled drug delivery system is promising for less dosing and higher patient compliance.

Keywords: Angiotensin II receptor antagonist, Hypertension, Matrix system, Control release.

(C) 2016 The Authors. Published by Innovare Academic Sciences Pvt Ltd. This is an open access article under the CC BY license (http://creativecommons. org/licenses/by/4. 0/) DOI: http://dx.doi.org/10.22159/ajpcr.2016.v9s3.14719

\section{INTRODUCTION}

For many years, drugs were discovered and used clinically for different diseases, but until now, there is no drug meets all biopharmaceutical requirements. Drugs used for cardiovascular diseases (CVDs) were discovered and developed. One of the drugs used for CVDs is candesartan cilexetil. Candesartan cilexetil is selective angiotensin II receptor antagonist mainly on the AT1 sub type receptors. Candesartan cilexetil has poor oral bioavailability $(<40 \%)$ and this due to firstpass metabolism in the liver [1]. The half-life of the drug is about 9 hrs and peak plasma concentration reaches after 4 hrs. Candesartan cilexetil solubility showed in spite of it present as a salt of weak acid practically insoluble in water and sparingly soluble in methanol. As oral bioavailability is low, frequent administration of the drug is intended to overcome the low bioavailability concerns. Frequent administration of drugs for long-term treatment for patients with chronic diseases such as hypertension is not desirable. Single dose administration in a day is one of the approaches to enhance patient compliance. Sustain release or controlled release tablet dosage form is one of the promising drug delivery systems used to decrease the frequency of the drug administration and to improve the bioavailability. Drugs with higher efficacy are prepared as controlled release tablets which are much better than conventional tablet dosage forms [2]. Extensive in vitro and in vivo studies of sustained release dosage forms are done to make it more safe and effective toward treatment of diseases. Matrix tablet is one of the approaches related to controlled release system. Matrix tablets must contain one or more polymer which controls or modulate the release of the drug from the tablet. Polymers are cross-linked with drug and the release mechanism depends on the type of the polymer used. Polymers are biodegradable, non-toxic, and safe like hydroxyl propyl methyl cellulose (HPMC) and xanthan gum [3].

Candesartan cilexetil was approved by FDA in September 2000 and presently marketed by AstraZeneca under the name "Atacand ${ }^{\circledR}$." Recent reports indicated its increase use, signifying its benefit in the treatment of stroke, heart failure, diabetic renal disease, and diabetic retinopathy.
Being a highly lipophilic drug ( $\log \mathrm{P}=6.1$ ) with low aqueous solubility of $5 \times 10^{-5} \mathrm{~g} / \mathrm{L}$, the drug is classified as a Class II drug according to the biopharmaceutical classification system [4].

A tablet is an important dosage form which considered the first preferable type for patient's use. It comprises a mixture of active substances and excipients, usually in powder form, a compressed form of powder into a solid dose. Over the past 30 years or more, the development and complication involved in marketing new drug molecules have increased, with related focusing on the therapeutic benefits of sustained drug delivery [5].

From the wide choice of matrix forming materials which are important in the preparation of controlled release formulations are polyethylene oxides (PEO), methacrylic polymers, guar gum, xanthan gum, sodium alginate, chitosan, poly (acrylic acids), etc. Among the variety of hydrophilic polymers used, PEO is one of the most important polymers used in the preparation of the matrix tablets due to their non-toxic, high water-soluble, and swellable. Methacrylic polymers (Eudragit) also attracted researchers in preparation of controlled release dosage forms, due to their high chemical stability, compatible, cost-effective, and sustain effect on the drug release. Natural gums hydrate and swell upon contact with water, and these have been used for the preparation of controlled release dosage forms [6]. For controlled release dosage form containing the drug dispersed uniformly in hydrophilic or hydrophobic polymers, the release of the drug is controlled by diffusion of the drug, or by surface erosion of the polymer in the medium, or by combination of the two mechanisms.

HPMC is one of the polymers used for the preparation of oral controlled drug delivery systems also natural gums have been used for the preparation of matrix tablets. Xanthan gum is a high molecular weight hetero polysaccharide gum which produced by a pure culture fermentation of carbohydrates with the microorganism Xanthomonas campestris. Xanthan gum has been used in oral and topical formulations like in cosmetics and foods industry also as suspending agent [7]. 
Granulation is a technique used in the preparation of tablets, in which it involves particles enlargement by agglomeration. In the granulation process, fine particles are converted into larger agglomerates by different mechanisms to granules. In general, granulation is preferred after an initial mixing of the powder ingredients along with the drug, so a uniform distribution of each ingredient throughout the powder mixture is achieved. Granules used in the pharmaceutical industry are primarily produced as an intermediary with a size range of $0.2-0.5 \mathrm{~mm}$ which either packed as a dosage form or mixed with other excipients before tablet. The preferred less costly granulation technique is dry granulation which could be achieved either by slugging for small scale production and roller compaction for large-scale production [8]. The rationale of this study is to prepare candesartan cilexetil matrix tablets by dry granulation technique using different polymers. Natural and synthetic polymers will affect the properties of candesartan cilexetil matrix tablets, so these tablets were evaluated for different evaluation parameters also the sustain release effect was studied to overcome frequent administration and enhance patient compliance.

\section{MATERIALS AND METHODS}

\section{Materials}

Chemicals

Candesartan cilexetil (Micro Labs, Bengaluru, India), Eudragit RS100 (HIMEDIA Laboratories, India), sodium carboxy methyl cellulose (NaCMC) (Sigma Chemical Co., USA), HPMC K100 (HIMEDIA Laboratories, India), xanthan gum (HIMEDIA Laboratories, India), acacia gum (Sigma-Aldrich Co., USA), Tragacanth (HIMEDIA Laboratories, India), talc (Afco., India), polyvinylpyrrolidone K30 (Riedel De Haen AG Seelze, Hannover, Germany), microcrystalline cellulose (Avecil ${ }^{\circledR}$ pH 102) (Sigma-Aldrich Co., USA), lactose (Riedel-deltaen, Germany), magnesium stearate (HIMEDIA Laboratories, India), disodium hydrogen orthophosphate, and potassium di hydrogen orthophosphate (SD FineChem Limited, Mumbai, India). All other chemicals and reagents used were of analytical grade.

\section{Instruments}

Tablet machine (Korsch EKO, Germany), manual hardness tester (Stokes, Monsanto Co. Ltd.), Vernier Calliper (model-Triclrbrand), Friabilator (Roche, Germany), ultraviolet (UV)-visible spectrophotometer (Carry win UV, Varian, Australia), Fourier transform infrared (FTIR) system (Shimadzu, Japan), pH meter (Hanna, Italy), FTIR System (FTIR-8400 Shimadzu, Japan), differential scanning calorimetry (DSC) (Shimadzu, Japan), and X-ray diffractometry (Philips Analytical PW 3710). Other assistant laboratory materials and instruments used were considered official and registered.

\section{Methods}

\section{Preparation of matrix tablets}

The method used for the preparation of tablets was dry granulation technique by slugging. In general, drug and other components for each formula are mixed without magnesium stearate (lubricant) in bottles, and then after the mixing for 15 minutes, half of the lubricant (magnesium stearate) was added and the mixture compressed into one slug tablet by single punch tablet machine. Slug tablet then weighed and calculated the real number of tablets in which this number will help in determining the remaining amount of lubricant used. After calculating the required amount of lubricant to be used, the slug was sieved to granules by siever and the resulted granules were ready for the second compression by adding the calculated amount of lubricant to the granules and compressed to obtain the tablets $[8,9]$.

Each tablet contained the drug in constant amounts for all formulas (16 mg), the polymers to be used for the study were (Eudragit RS100, NaCMC, HPMC K100, xanthan gum, acacia and tragacanth) in the ratio $1: 1,1: 2$, and $1: 3$, and the other excipients were used in constant ratios for all formulas as shown in Table $1 \mathrm{a}$.
Combination of two polymers (either natural or synthetic polymer combination) in the ratio 1:1:1 also prepared as shown in Table $1 \mathrm{~b}$.

\section{Evaluation of the granules}

Before compression step into tablets, the granules were evaluated for some evaluation properties such as angle of repose which done by funnel method, bulk density, tapped density, compressibility index (CI), and Hauser's ratio as shown in Table $2[10,11]$. Tapped bulk density (TBD), loose bulk density (LBD), and CI were calculated by using the following equations:

$$
\begin{aligned}
& \mathrm{TBD}=\frac{\text { Weight of the powder }}{\text { Final volume }} \\
& \mathrm{LBD}=\frac{\text { Weight of the powder }}{\text { Initial volume }} \\
& \text { Carr's compressibility index }=\left[\frac{(\mathrm{TBD}-\mathrm{LBD}) \times 100}{\mathrm{TBD}}\right]
\end{aligned}
$$

Hausner's ratio $=\frac{\text { TBD }}{\text { LBD }}$

\section{Evaluation of tablets}

The prepared tablets were evaluated for weight variation, drug content, friability, hardness, and thickness as shown in Table 3, swelling index as shown in Table 4 and Fig. 1 and in vitro dissolution test [11].

\section{Weight variation}

20 tablets were randomly selected from each formula (F1 to F24), and the average weight of these tablets was measured. According to the United State Pharmacopeia (USP), not more than 2 of individual weights of tablets were out of the average by more than the percentage deviation and none deviate twice the percentage. The official limit of percentage deviation in this study is $7.5 \%$ because the total weight of the tablet is $150 \mathrm{mg}$ which lies in the range between 130 and $324 \mathrm{mg}[11,12]$.

\section{Drug content}

The amount of candesartan cilexetil in each tablet for each formula was measured using a UV spectrophotometer. The tablet was dissolved in small volume of methanol and then suitable dilution of the methanol in volumetric flasks using a buffer ( $\mathrm{pH}$ 6.8) and read the solution at $255 \mathrm{~nm}$ which is the wave length of candesartan cilexetil [13]. The amount of candesartan cilexetil was measured from the recorded absorbance that obtained from the spectrophotometer, and the concentration of the dug in solution was measured from the equation obtained from the calibration curve in 6.8 buffer solution.

\section{Friability, hardness, and thickness}

Random 20 tablets were taken for evaluation from each formula. According to the USP, the accepted value must be $<1 \%$. Friability measured using Roche friabilator ( $25 \mathrm{rpm}$ for 4 minutes). The friability value was calculated using the following equation [14]:

$\mathrm{F} \%=\frac{\mathrm{W}_{\text {initial }}-\mathrm{W}_{\text {final }}}{\mathrm{W}_{\text {initial }}} \times 100$

10 tablets were taken randomly for hardness test from each formula. The hardness was measured using Monsanto ${ }^{\circledR}$ manual hardness tester, and the average value for the tablets was measured [14].

Five tablets from each formula were taken randomly, and the average thickness of the tablets was calculated using Vernier caliper scale $[12,14]$.

\section{Determination of swelling index}

The swelling behavior of matrix tablets was determined at $37 \pm 0.5^{\circ} \mathrm{C}$ in phosphate buffer ( $\mathrm{pH}$ 6.8). Three tablets from each formula were individually kept in a glass Petri dish which containing $50 \mathrm{ml}$ of the 
Table 1a: Preparation of different formulas of matrix tablets containing one polymer with different ratios

\begin{tabular}{|c|c|c|c|c|c|c|c|c|c|c|c|c|c|c|c|c|c|c|}
\hline Ingredients (mg) & F1 & F2 & F3 & F4 & F5 & F6 & F7 & F8 & F9 & F10 & F11 & F12 & F13 & F14 & F15 & F16 & F17 & F18 \\
\hline Candesartan & 16 & 16 & 16 & 16 & 16 & 16 & 16 & 16 & 16 & 16 & 16 & 16 & 16 & 16 & 16 & 16 & 16 & 16 \\
\hline Eudragit RS 100 & 16 & 32 & 48 & - & - & - & - & - & - & - & - & - & - & - & - & - & - & - \\
\hline Sodium CMC & - & - & - & 16 & 32 & 48 & - & - & - & - & - & - & - & - & - & - & - & - \\
\hline НРМС К 100 & - & - & - & - & - & - & 16 & 32 & 48 & - & - & - & - & - & - & - & - & - \\
\hline Xanthan gum & - & - & - & - & - & - & - & - & - & 16 & 32 & 48 & - & - & - & - & - & - \\
\hline Acacia gum & - & - & - & - & - & - & - & - & - & - & - & - & 16 & 32 & 48 & - & - & - \\
\hline Tragacanth & - & - & - & - & - & - & - & - & - & - & - & - & - & - & - & 16 & 32 & 48 \\
\hline PVP K 30 & 16 & 16 & 16 & 16 & 16 & 16 & 16 & 16 & 16 & 16 & 16 & 16 & 16 & 16 & 16 & 16 & 16 & 16 \\
\hline MCC & 16 & 16 & 16 & 16 & 16 & 16 & 16 & 16 & 16 & 16 & 16 & 16 & 16 & 16 & 16 & 16 & 16 & 16 \\
\hline Lactose & 72 & 56 & 40 & 72 & 56 & 40 & 72 & 56 & 40 & 72 & 56 & 40 & 72 & 56 & 40 & 72 & 56 & 40 \\
\hline Mg stearate & 5 & 5 & 5 & 5 & 5 & 5 & 5 & 5 & 5 & 5 & 5 & 5 & 5 & 5 & 5 & 5 & 5 & 5 \\
\hline Total weight & 150 & 150 & 150 & 150 & 150 & 150 & 150 & 150 & 150 & 150 & 150 & 150 & 150 & 150 & 150 & 150 & 150 & 150 \\
\hline
\end{tabular}

CMC: Carboxy methyl cellulose, HPMC: Hydroxyl propyl methyl cellulose, PVP: Polyvinylpyrrolidone

Table 1b: Preparation of different formulas of matrix tablets containing combination of two polymers with 1:1 ratio

\begin{tabular}{|c|c|c|c|c|c|c|}
\hline Ingredients (mg) & F19 & F20 & F21 & F22 & F23 & F24 \\
\hline Candesartan & 16 & 16 & 16 & 16 & 16 & 16 \\
\hline Eudragit RS 100 & 16 & 16 & - & - & - & - \\
\hline Sodium CMC & 16 & - & 16 & - & & \\
\hline HPMC K 100 & - & 16 & 16 & - & - & - \\
\hline Xanthan gum & - & - & - & 16 & 16 & - \\
\hline Acacia gum & - & - & - & 16 & - & 16 \\
\hline Tragacanth & - & - & - & - & 16 & 16 \\
\hline PVP K 30 & 16 & 16 & 16 & 16 & 16 & 16 \\
\hline MCC & 16 & 16 & 16 & 16 & 16 & 16 \\
\hline Lactose & 72 & 56 & 40 & 72 & 56 & 40 \\
\hline Mg stearate & 5 & 5 & 5 & 5 & 5 & 5 \\
\hline Total weight & 150 & 150 & 150 & 150 & 150 & 150 \\
\hline
\end{tabular}

MCC: Microcrystalline cellulose, CMC: Carboxy methyl cellulose, HPMC: Hydroxyl propyl methyl cellulose, PVP: Polyvinylpyrrolidone

Table 2: Evaluation of the granules

\begin{tabular}{|c|c|c|c|c|c|c|c|}
\hline Formula & $\begin{array}{l}\text { Angle of repose } \\
\left(\theta^{\circ}\right)\end{array}$ & Type of flow & $\begin{array}{l}\text { Bulk density } \\
(\mathrm{g} / \mathrm{ml})\end{array}$ & $\begin{array}{l}\text { Tapped density } \\
(\mathrm{g} / \mathrm{ml})\end{array}$ & $\begin{array}{l}\text { Compressibility index } \\
(\%)\end{array}$ & Type of flow & Hausner's ratio \\
\hline F1 & $32 \pm 1.7$ & Good & $0.39 \pm 0.031$ & $0.44 \pm 0.021$ & $11 \pm 0.01$ & Good & $1.12 \pm 0.1$ \\
\hline F2 & $30 \pm 1.2$ & Excellent & $0.44 \pm 0.042$ & $0.51 \pm 0.011$ & $13.7 \pm 0.02$ & Good & $1.15 \pm 0.23$ \\
\hline F3 & $31 \pm 1.1$ & Good & $0.45 \pm 0.024$ & $0.53 \pm 0.041$ & $15 \pm 0.01$ & Good & $1.17 \pm 0.15$ \\
\hline F4 & $34 \pm 1.6$ & Good & $0.38 \pm 0.017$ & $0.46 \pm 0.033$ & $17 \pm 0.02$ & Fair & $1.21 \pm 0.3$ \\
\hline F5 & $38 \pm 1.2$ & Fair & $0.47 \pm 0.039$ & $0.56 \pm 0.025$ & $16 \pm 0.02$ & Fair & $1.19 \pm 0.2$ \\
\hline F6 & $35 \pm 1.8$ & Good & $0.48 \pm 0.023$ & $0.54 \pm 0.017$ & $11.1 \pm 0.03$ & Good & $1.29 \pm 0.13$ \\
\hline F8 & $33 \pm 1.1$ & Good & $0.51 \pm 0.034$ & $0.59 \pm 0.014$ & $13.5 \pm 0.01$ & Good & $1.27 \pm 0.1$ \\
\hline F9 & $35 \pm 1.2$ & Good & $0.55 \pm 0.031$ & $0.67 \pm 0.029$ & $18 \pm 0.02$ & Fair & $1.22 \pm 0.19$ \\
\hline F10 & $33 \pm 1.5$ & Good & $0.43 \pm 0.031$ & $0.50 \pm 0.033$ & $14 \pm 0.04$ & Good & $1.4 \pm 0.2$ \\
\hline F11 & $36 \pm 1.3$ & Fair & $0.46 \pm 0.021$ & $0.52 \pm 0.021$ & $11.5 \pm 0.03$ & Good & $1.28 \pm 0.21$ \\
\hline F12 & $32 \pm 1.5$ & Good & $0.47 \pm 0.032$ & $0.58 \pm 0.034$ & $19 \pm 0.02$ & Fair & $1.23 \pm 0.1$ \\
\hline F13 & $34 \pm 1.9$ & Good & $0.57 \pm 0.03$ & $0.72 \pm 0.04$ & $20.8 \pm 0.03$ & Fair & $1.26 \pm 0.3$ \\
\hline F14 & $33 \pm 1.1$ & Good & $0.33 \pm 0.024$ & $0.39 \pm 0.012$ & $15.3 \pm 0.01$ & Good & $1.48 \pm 0.1$ \\
\hline F15 & $38 \pm 2$ & Fair & $0.54 \pm 0.012$ & $0.62 \pm 0.031$ & $12.9 \pm 0.02$ & Good & $1.36 \pm 0.5$ \\
\hline F17 & $35 \pm 1.3$ & Good & $0.32 \pm 0.025$ & $0.39 \pm 0.021$ & $17.9 \pm 0.03$ & Fair & $1.5 \pm 0.2$ \\
\hline F18 & $31 \pm 1.5$ & Good & $0.4 \pm 0.012$ & $0.46 \pm 0.015$ & $13 \pm 0.03$ & Good & $1.32 \pm 0.3$ \\
\hline F19 & $36 \pm 1.4$ & Fair & $0.3 \pm 0.023$ & $0.37 \pm 0.026$ & $18.9 \pm 0.02$ & Fair & $1.36 \pm 0.29$ \\
\hline F20 & $34 \pm 1.1$ & Good & $0.33 \pm 0.02$ & $0.4 \pm 0.021$ & $17.5 \pm 0.03$ & Fair & $1.39 \pm 0.3$ \\
\hline F21 & $35 \pm 2.2$ & Good & $0.5 \pm 0.014$ & $0.59 \pm 0.032$ & $15.2 \pm 0.03$ & Good & $1.3 \pm 0.4$ \\
\hline F22 & $37 \pm 2.4$ & Fair & $0.43 \pm 0.029$ & $0.49 \pm 0.05$ & $12.2 \pm 0.02$ & Good & $1.32 \pm 0.2$ \\
\hline F23 & $36 \pm 1.9$ & Fair & $0.35 \pm 0.034$ & $0.40 \pm 0.019$ & $12.5 \pm 0.03$ & Good & $1.34 \pm 0.5$ \\
\hline F24 & $39 \pm 1.6$ & Fair & $0.4 \pm 0.036$ & $0.45 \pm 0.032$ & $11.1 \pm 0.02$ & Good & $1.3 \pm 0.1$ \\
\hline
\end{tabular}

buffer solution. The weight of individual tablet was taken before the swelling study $\left(\mathrm{M}_{0}\right)$. The tablet was kept in a basket. The weight of a tablet was taken at time intervals of $2,4,6$, and $8 \mathrm{hrs}$, and at the end of this time, the tablet was removed, polished with a tissue paper, and weighed again $\left(\mathrm{M}_{\mathrm{t}}\right)$ [15].
Percent hydration (swelling index) was calculated as shown in Fig. 1 using the following formula $[15,16]$ :

Swelling index $=\frac{M_{t}-M_{0}}{M_{0}} \times 100$ 
Table 3: Evaluation parameters of the tablets

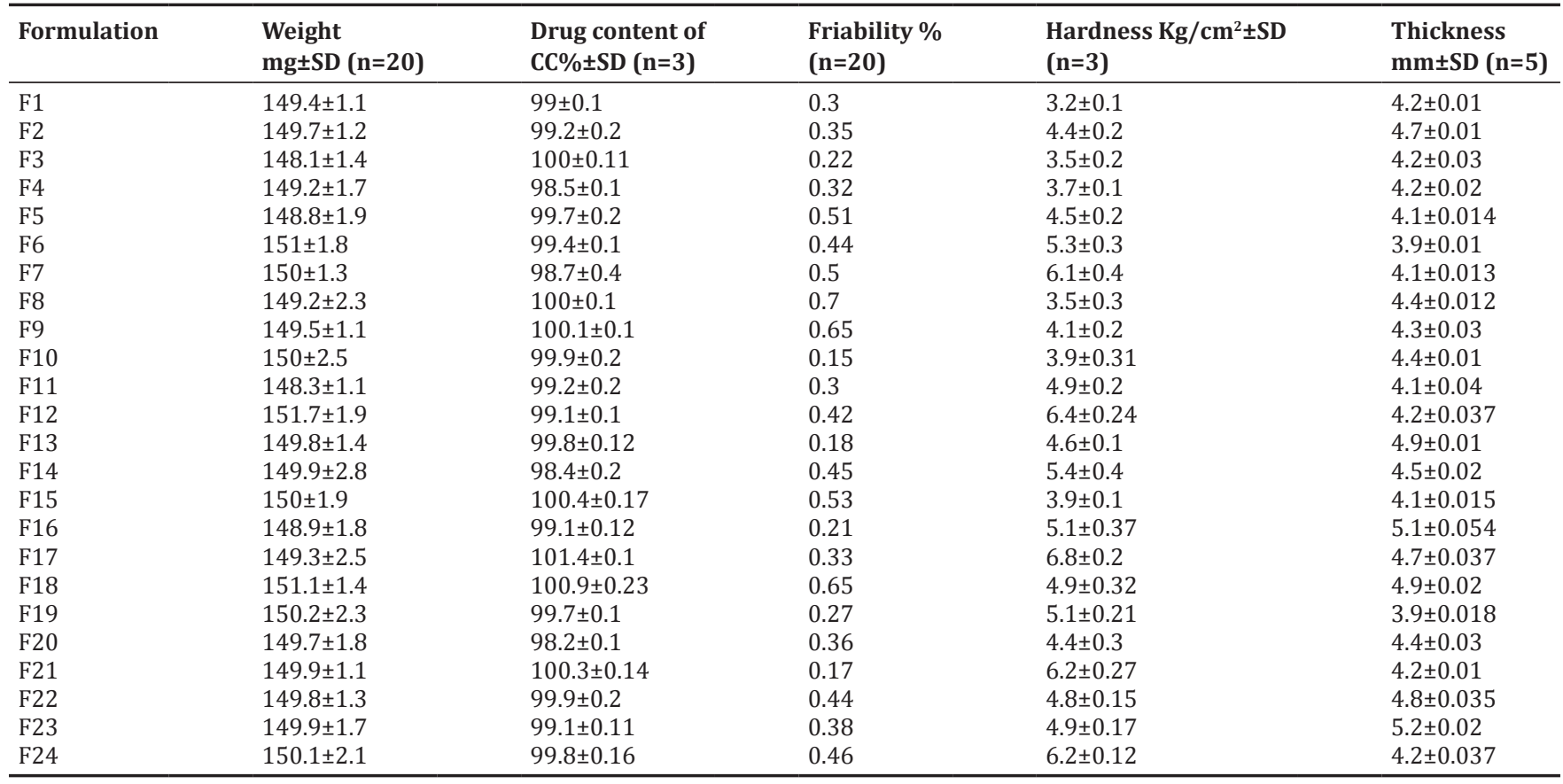

SD: Standard deviation

Table 4: Saturation solubility of candesartan cilexetil in various solvents

\begin{tabular}{ll}
\hline Solvent & $\begin{array}{l}\text { Solubility } \\
\text { (mg/ml) } \pm \text { S.D.* }\end{array}$ \\
\hline HCL medium pH (1.2) & $0.0099 \pm 0.0006$ \\
Buffer medium pH (6.8) & $0.029 \pm 0.004$ \\
HCL medium (pH 1.2) with 0.35\% polysorbate 20 & $0.093 \pm 0.008$ \\
Buffer medium (pH 6.8) with 0.35\% polysorbate 20 & $0.416 \pm 0.012$ \\
Glycerin & $0.174 \pm 0.021$ \\
PG & $0.463 \pm 0.064$ \\
PEG 200 & $2.8 \pm 0.13$ \\
PEG 400 & $4.23 \pm 0.11$ \\
\hline
\end{tabular}

SD from mean ( $n=3)$. PEG: Poly ethylene glycol

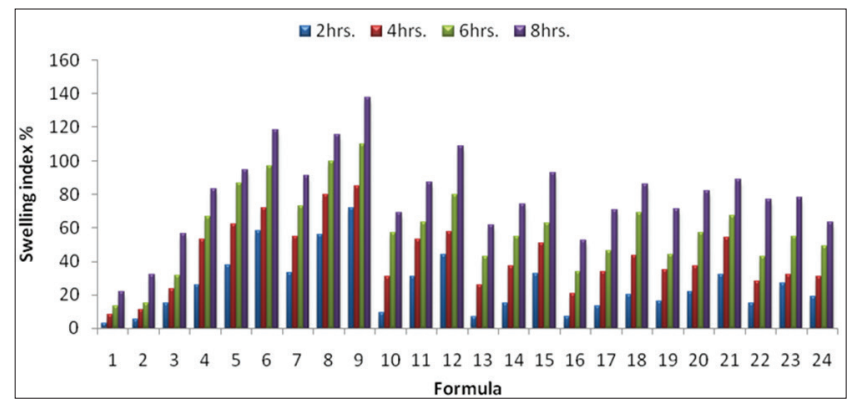

Fig. 1: Swelling index histogram for the prepared formulas every 2 hrs interval

Where, $\mathrm{M}_{t}$ and $\mathrm{M}_{0}$ are the weight of tablet at time $=\mathrm{t}$ and time $=0$, respectively.

\section{In vitro drug dissolution}

In vitro dissolution of candesartan cilexetil was carried out using dissolution apparatus Type II (paddle type), in which the paddle speed was at $50 \mathrm{rpm}$ and using $900 \mathrm{ml}$ buffer solution $(\mathrm{pH} 6.8)$ at $37^{\circ} \mathrm{C}$. The procedure last $8 \mathrm{hrs}$ long $(\mathrm{n}=8)$ depends on the polymer type and/or concentration used of the polymer and how it will affect the release profile of the drug from the formulas (F1 to F24). Samples $(10 \mathrm{ml})$ were withdrawn every $1 \mathrm{hr}$ and replaced with the same amount of fresh buffer (pH 6.8) to maintain sink condition, and these samples were collected and the absorbance values of the drug from those samples were measured using UV-visible spectroscopy at $255 \mathrm{~nm}$ and then determine the amount of drug in each sample using the equation obtained from the calibration curve [5].

\section{6-kinetics of drug release profile}

The cumulative amounts of candesartan cilexetil released from a tablet from different formulas were fitted to four models which are zero order kinetics, first order kinetics, Higuchi model, and Korsmeyer-Peppas model. These models were used to determine the mechanism of drug release [12].

\section{Statistical analysis}

The one-way analysis of variance test was used to determine the significance of difference among the results obtained from the studied formulations. The level of significance was set at ( $\alpha 0.05)$, in which less than this value was considered to be statistically significant and more than this was considered statistically insignificant.

\section{RESULTS}

Evaluation of granules for all formulas (F1 to F24) was done and the results showed in Table 2. Angle of repose for each formula was measured, and results showed excellent and good flow for all the formulas except formulas (F5, F11, F15, F16, F19, F22, F23, and F24), these formulas showed fair flow.

CI which was calculated by equation 3 showed most of the formulas was having good compressibility except for formulas (F4, F5, F9, F12, F13, F16, F17, F19, and F20) which they were showed fair CI. Results showed that Hausner ratio values were of $<1.25$ indicates a good flow of granules, whereas $>1.5$ indicates poor flow, in which Hausner ratio is a measure of the interparticulate friction. Lower CI or lower Hausner ratios of granules indicates better flow properties than higher values as shown in Table 2 .

Results for the evaluation of tablets were shown in Table 3; weight variation study was considered within the accepted range as stated by the USP for all the formulas. 
Drug content measurements were within the accepted values. Friability measurements were accepted for all formulas because the values obtained were $<1 \%$ as stated by the USP. Hardness values were within the range of sustained or controlled release tablet type. Thickness values showed acceptable properties and complied with pharmacopeia specifications [12]

The results of the swelling behavior are shown in Fig. 1. The swelling index indicates the ability of polymer to absorb water from dissolution media and swells. The water absorption and swelling of the tablets started slowly and continued during the time of the experiment. The time was set for $8 \mathrm{~h}$ and the tablet weighed every $2 \mathrm{hrs}$.

Samples $(10 \mathrm{ml})$ were taken every $1 \mathrm{hr}$, and the absorbance was measured by UV spectroscopy. Each absorbance value was used to calculate the concentration the drug release at the predetermined time. The collected results were done in triplicate $(n=3)$.

Polymers used in different amounts either as a single polymer or in a combination of two polymers. From F1 to F18 in which single polymer was used in each formula, the release of candesartan cilexetil was affected by the type of the polymer and the amount of the polymer used, whereas from F19 to F24, in which combination of two polymers were used (synthetic or natural), the drug release affected by both polymers from the matrix tablet.

Six polymers were primarily used for preparation of matrix tablets, in which they were Eudragit RS100, HPMC K100M, NaCMC, xanthan gum, acacia gum, and tragacanth.

Formulas (F1, F4, F7, F10, F13, and F16) contain single polymer, in which they were eudragit RS100, NaCMC, HPMC K100M, xanthan gum, acacia gum, and tragacanth, respectively. All these formulas had the same amount of drug in each tablet (16 mg), i.e., (1:1) ratio to the drug.

The effect of the type of polymer on the release profile of candesartan cilexetil was shown in Fig. 2. F13 had faster release (100\% after $4 \mathrm{hrs}$ ) which contained acacia gum and the slowest release was showed for F7 (73\% after $8 \mathrm{hrs)}$ which contained HPMC K100M. From these results, F7 was considered the most sustain release formula and used for further evaluation-like IR, DSC, and X-ray diffraction.

F1 was an $89 \%$ release after 8 hrs which contains eudragit RS100; F4 was a $100 \%$ release after 5 hrs which contains NaCMC; F10 was a 100\% after 8 hrs which contains xanthan gum; F16 was a 100\% release after 5 hrs which contains tragacanth polymer as shown in Fig. 2.

Each polymer used in three different amounts $(16,32$, and $48 \mathrm{mg}$ ) for preparation of matrix tablets. The effect of the amount of polymer used on the release profile of candesartan cilexetil was shown in Figs. 3-8, respectively. As shown in Fig. 3, the use of eudragit RS100 in different amounts as shown in F1, F2, and F3, respectively, the release was retarded and sustained from the tablet when the amount of polymer in the tablet was increased in respect to the amount of the drug. F9 had a slower release $\left({ }^{*} \mathrm{p}<0.05\right)$ than $\mathrm{F} 7$ and $\mathrm{F} 8$, respectively, as shown in Fig. 5. These results indicated that increase in the amount of polymer in the tablet will provide more gelation of the tablet, and this will, in turn, lead to retardation in the release of the drug from the system. This effect was observed with the use of other polymers, in which the release of drug from matrix tablet retarded by increase the polymer to drug ratio [14].

A combination of two different polymers in ratio (1:1) also studied. The combination was selected according to the source of the polymer used so in case of F19, F20, and F21, the polymer combination used was of synthetic source, whereas F22, F23, and F24 the polymer combination used was of natural source.

The release of the drug was retarded from all the formulas $\left({ }^{*} \mathrm{p}<0.05\right)$ as shown in Fig. 9, and this due to the effect of the polymers, in which more than one mechanism of release would involve in the release of drug substances such as swelling, pH dependent, and floating [7]

The IR spectra of pure drug candesartan cilexetil show characteristic absorption peaks as shown in Table 5 and Fig. 10. These peaks were presented in the IR scan of the matrix tablet; the most sustain formula which consists of candesartan cilexetil and HPMC K100M (F7) was used for IR study.

DSC thermogram showed a sharp characteristic endothermic peak of candesartan cilexetil around its melting point as shown in Fig. 11; such peak indicates that candesartan cilexetil used is in the pure crystalline state.

DSC thermogram for F7 which contains candesartan cilexetil and HPMC K100M showed a characteristic endothermic peak of candesartan cilexetil. This peak corresponding to the drug melting which was appeared with small shifting and reduce the intensity which indicated that the drug is still in the crystal form as shown in Fig. 12 [13].

The X-ray diffraction pattern of candesartan cilexetil indicates that the drug present in crystal form due to the presence of sharp peaks as shown in Fig. 13, whereas in F7, the X-ray diffraction indicated that most characteristic peaks shown by pure candesartan cilexetil were absent, and others were appearing with the markedly reduced intensity as shown in Fig. 14. These observed peaks indicated that drug crystalline

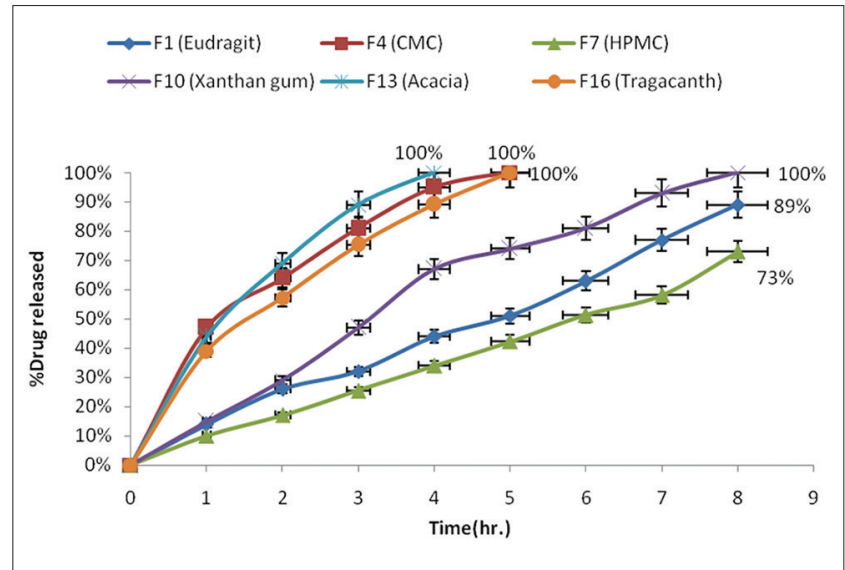

Fig. 2: In-vitro dissolution for studying the effect of type of polymer on the release profile of candesartan cilexetil in 6.8 buffer solution (F1 contain eudragit RS100, F4 contain NaCMC,

F7 contain HPMC K100M, F10 xanthan gum, F13 contain acacia and F16 contain tragacanth)

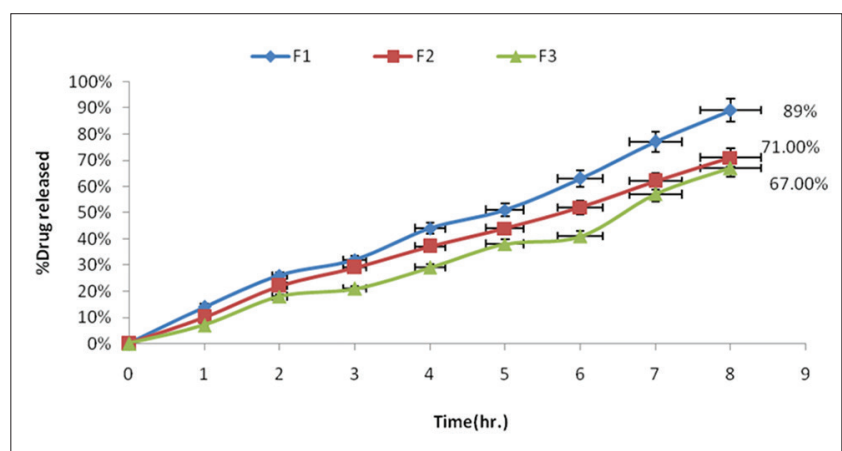

Fig. 3: In vitro dissolution for studying the effect of amount of polymer on the in vitro release profile of candesartan cilexetil from matrix tablets contain eudragit RS100 polymer in 6.8 buffer (F1: 16 mg eudragit, F2: 32 mg eudragit and F3: 48 mg eudragit) 


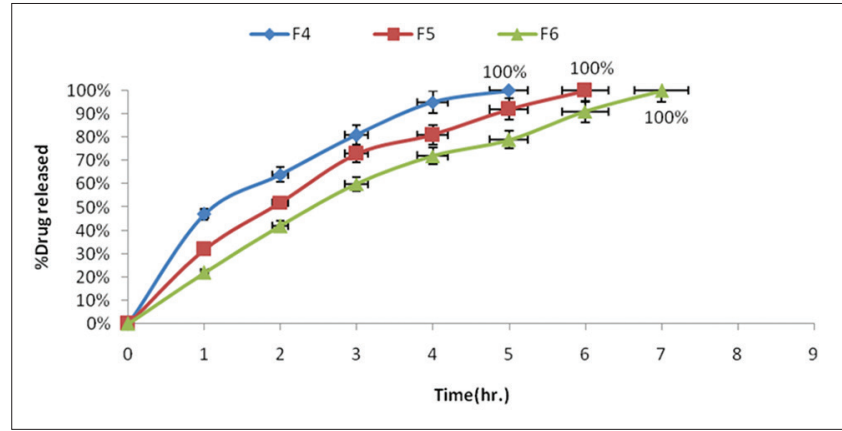

Fig. 4: In vitro dissolution for studying the effect of amount of polymer on the in vitro release profile of candesartan cilexetil from matrix tablets contain NaCMC polymer in 6.8 buffer (F4: 16 mg NaCMC, F5: $32 \mathrm{mg}$ NaCMC and F6: $48 \mathrm{mg}$ NaCMC)

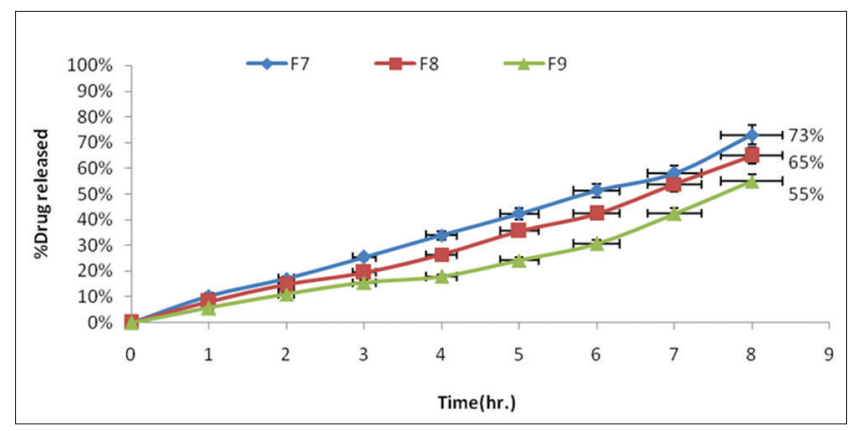

Fig. 5: In vitro dissolution for studying the effect of amount of polymer on the in vitro release profile of candesartan cilexetil from matrix tablets contain HPMC K100M polymer in 6.8 buffer (F7: 16 mg HPMC K100M, F8: $32 \mathrm{mg}$ HPMC K100M and F9: $48 \mathrm{mg}$ HPMC K100M)

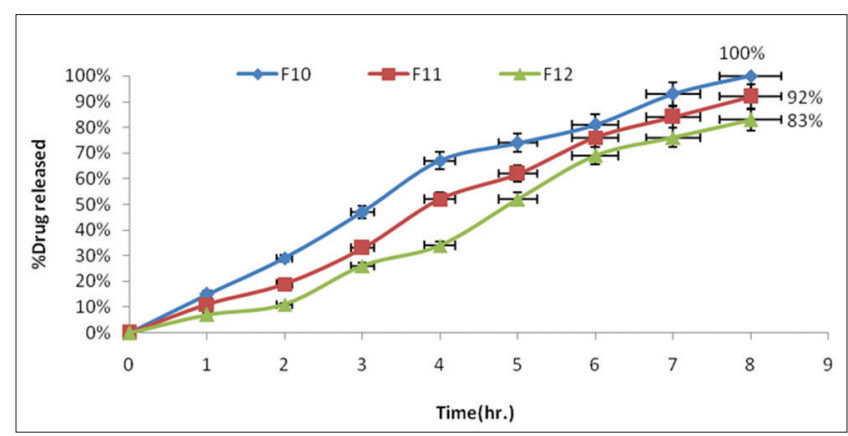

Fig. 6: In vitro dissolution for studying the effect of amount of polymer on the in vitro release profile of candesartan cilexetil from matrix tablets contain xanthan gum polymer in 6.8 buffer

(F10: $16 \mathrm{mg}$ xanthan gum, F11: $32 \mathrm{mg}$ xanthan gum and F12: 48 mg xanthan gum)

structure remained unchanged after the physical mixing of components and tablet compression [13].

The in vitro release study for the formulas (F1, F4, F7, F10, F13, and F16) was applied to four kinetic models, in which they are zero order first order, and Higuchi and Korsmeyer-Peppas models. The mechanism of drug release for candesartan cilexetil was determined by measuring the rate constant, the high correlation coefficient $\left(R^{2}\right)$, and the bestfitted line as shown in Table 6.

\section{DISCUSSION}

Differences in angle of repose were due to different reasons the important one is the amount of lubricant used. Magnesium stearate

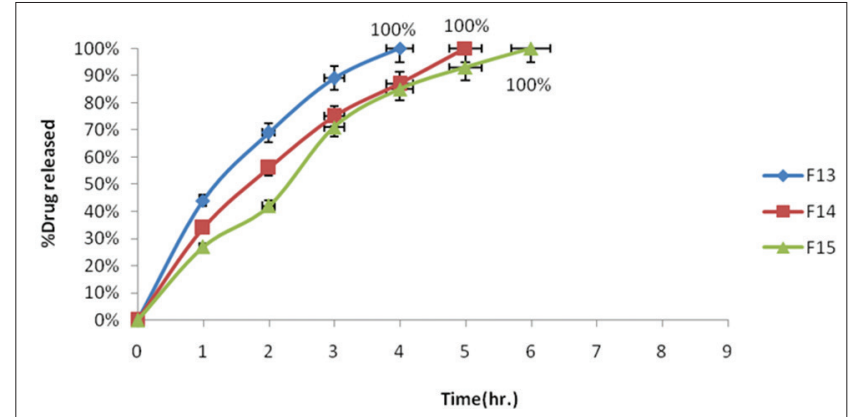

Fig. 7: In vitro dissolution for studying the effect of amount of polymer on the in vitro release profile of candesartan cilexetil from matrix tablets contain acacia gum polymer in 6.8 buffer (F13: $16 \mathrm{mg}$ acacia, F14: $32 \mathrm{mg}$ acacia and F15: $48 \mathrm{mg}$ acacia)

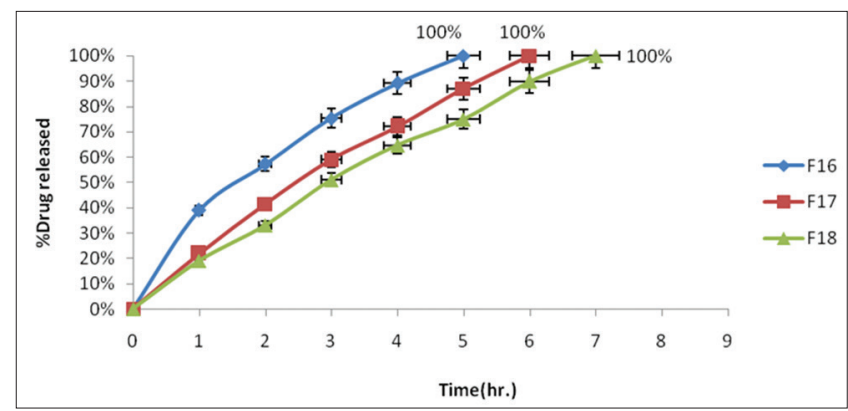

Fig. 8: In vitro dissolution for studying the effect of amount of polymer on the in vitro release profile of candesartan cilexetil from matrix tablets contain tragacanth polymer in 6.8 buffer (F16: $16 \mathrm{mg}$

tragacanth, F17: $32 \mathrm{mg}$ tragacanth and F18: $48 \mathrm{mg}$ tragacanth)

is used as lubricant in small amount. It is a cohesive material and so will help in decrease the powder dust during the filling and so will enhance granules flowability. Larger amount of lubricant may decrease the flowability of the granules [17]. Good lubricated granules will show good flow properties in comparing to less lubricated granules. Angle of repose test showed that the $\theta$ values increased when the concentration of lubricant was from $0 \%$ to $0.25 \%$, but increasing the concentration up to $1.5 \%$, it remained constant, so this gave indication that the flow improved with low amounts of lubricant after which there was no change [17]. CI related to the granular bridge strength and to the stability of the bridges, as the strength increase the CI became good to excellent [18]. Swelling of the polymer matrix will lead to delay the release of candesartan cilexetil from the tablet due to increase in diffusion path length. The swelling index depends the type of polymer used in which the results showed that the polymers used in the study could be arranged according to the ability to absorb water from the buffer solution from the higher to the lower degree of swelling as follows HPMC K100M > NaCMC > xanthan gum > acacia > tragacanth > eudragit RS100. From these results, the higher swelling was obtained in the formulas containing HPMC K100M and this due to the hydrophilicity of the polymer. While the hydrophobic polymer eudragit RS100 showed the lower swelling capacity [6].

The mechanism of swelling was initiated with polymer being swollen, and then, a viscous gel layer was formed, and at this point, the drug started to release slowly forms the matrix system $[6,19]$. In vitro dissolution studies in buffer media $\mathrm{pH}$ 6.8, results showed that the release of the drug from the matrix system affected by different factors such as the amount of polymer used in each formula, the type of the polymer used if it is hydrophilic or hydrophobic, and the source of the polymer if it was natural or synthetic polymer.

The saturation solubility of candesartan cilexetil was the main factor affecting the dissolution of the drug from the dissolution media. 
Table 5: Characteristic IR peaks of candesartan cilexetil

\begin{tabular}{ll}
\hline Functional group & $\begin{array}{l}\text { Characteristic peaks of candesartan } \\
\text { cilexetil observed in IR region } \mathbf{( \mathbf { c m } ^ { - 1 } \mathbf { ) }}\end{array}$ \\
\hline Aromatic C-H stretching & 2941.24 \\
C=O stretching & 1755.1 \\
C-N stretching & 1614.31 \\
-C-O stretching & 1244 \\
O-substitution & 750.26 \\
\hline
\end{tabular}

IR: Infrared

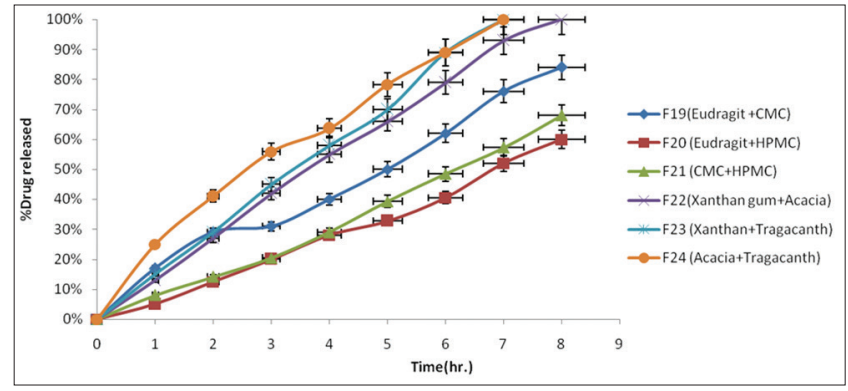

Fig. 9: In vitro dissolution for studying the effect of combination of two polymers (1:1) on the in vitro release profile of candesartan cilexetil from matrix tablets
Different studies showed that the drug was practically insoluble in buffer solution $\mathrm{pH} 6.8$ and so surfactant must be used to increase the solubility and to achieve sink condition. The solubility of the drug was differing from solvent to other and the choice of solvent is depend on the purpose of the study. The solubility of the drug in various solvents was given in Table 4 [13]. The order of increasing solubility as follows: Poly ethylene glycol (PEG) $400>$ PEG $200>$ PG > phosphate buffer (pH 6.8) with $0.35 \%$ polysorbate $20>$ glycerin $>$ HCL solution ( $\mathrm{pH} 1.2$ ) with $0.35 \%$ polysorbate $20>$ phosphate buffer $(\mathrm{pH} 6.8)>$ HCL solution (pH 1.2). The high solubility of candesartan cilexetil in PEG 400 is due to the longer non-polar chain of PEG 400 as the longest non-polar chain reflects the hydrophobic interactions of the drug with the liquid-vehicle molecule [20].

Increase in the $\mathrm{pH}$ of the medium resulted in an increase in the solubility of candesartan cilexetil; this is due to candesartan cilexetil is an acidic drug molecule also the use of polysorbate 20 as a surfactant increase the solubility of candesartan cilexetil in both HCL and buffer media. These results showed in Table $4[21,22]$. The solubility of candesartan was very slightly soluble in buffer solution $(\mathrm{pH}$ 6.8) and so Tween 20 (polysorbate 20) which is safe and non-toxic with concentration $(0.35 \% \mathrm{w} / \mathrm{w})$ was used to increase solubility of the drug in the dissolution media $[2,23]$.

Mechanism of dissolution if it was swelling, $\mathrm{pH}$ dependent, and floating was affected greatly by the type of the polymer used [24].

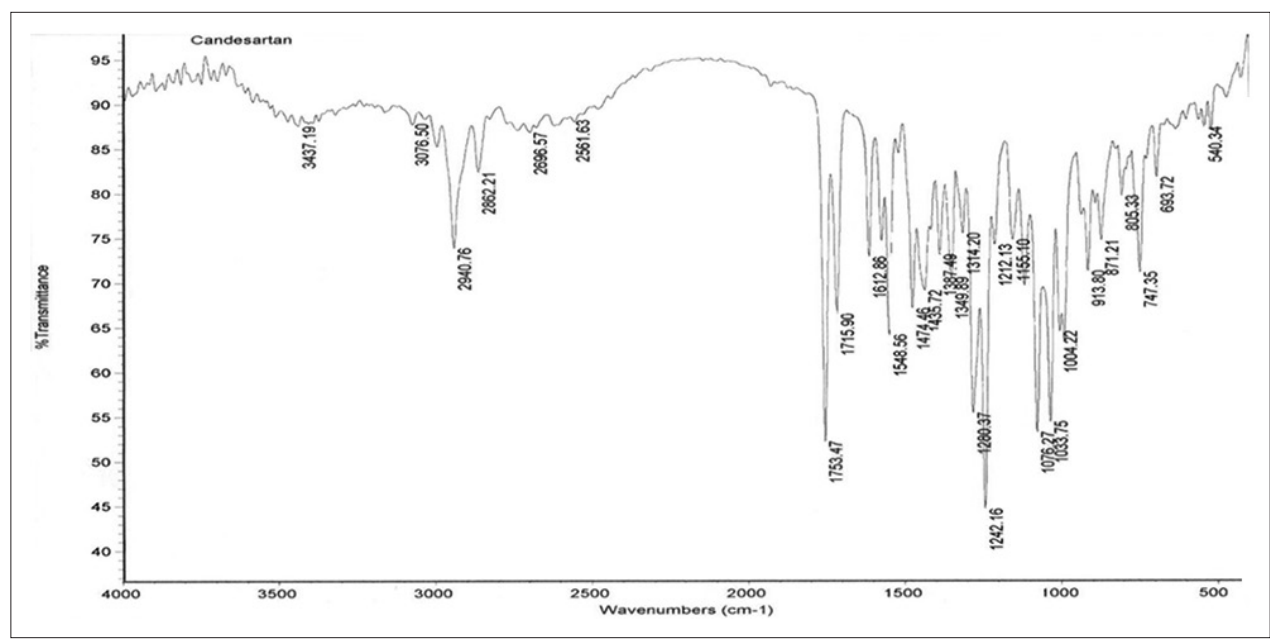

Fig. 10: Fourier transform infrared spectra of pure powder of candesartan cilexetil [29]

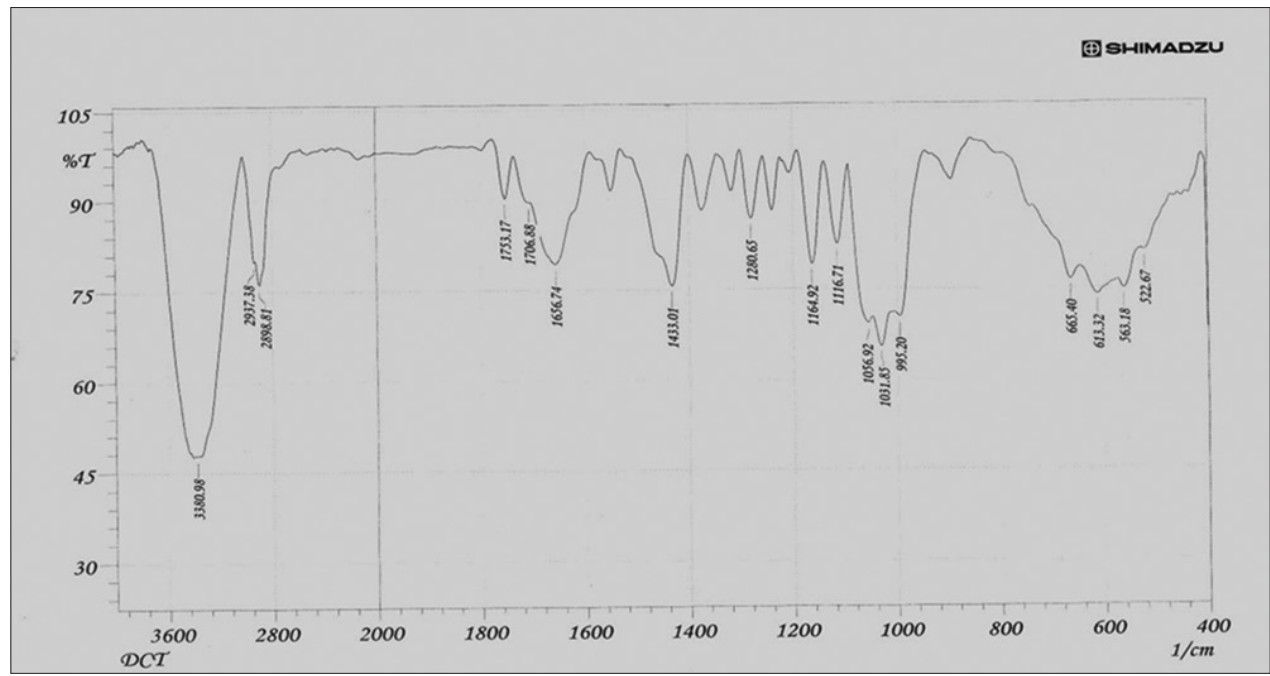

Fig. 11: FT-IR spectra of candesartan cilexetil and HPMC K100 physical mixture (1:1) 
Table 6: Correlation coefficients of different mathematical models for selected formulations

\begin{tabular}{|c|c|c|c|c|c|c|c|c|c|}
\hline \multirow[t]{2}{*}{ Formula code } & \multicolumn{2}{|c|}{ Zero order } & \multicolumn{2}{|c|}{ First order } & \multicolumn{2}{|c|}{ Higuchi model } & \multicolumn{3}{|c|}{ Korsmeyer-Peppas model } \\
\hline & $\mathbf{k}_{0}$ & $\mathbf{R}^{2}$ & $\mathbf{k}_{1}$ & $\mathbf{R}^{2}$ & $\mathbf{k}_{\mathrm{H}}$ & $\mathbf{R}^{2}$ & kKp & $\mathbf{R}^{2}$ & $\mathbf{n}$ \\
\hline F1 & 10.892 & 0.9893 & 0.170 & 0.9113 & 25.500 & 0.8188 & 11.410 & 0.9880 & 0.974 \\
\hline F7 & 8.659 & 0.9925 & 0.120 & 0.9387 & 20.184 & 0.7967 & 8.070 & 0.9921 & 1.039 \\
\hline F10 & 13.672 & 0.9504 & 0.261 & 0.9226 & 32.339 & 0.8757 & 19.367 & 0.9770 & 0.806 \\
\hline F13 & 28.300 & 0.6746 & 0.645 & 0.9484 & 49.573 & 0.9764 & 45.619 & 0.9881 & 0.581 \\
\hline F16 & 22.467 & 0.7333 & 0.493 & 0.9519 & 43.475 & 0.9788 & 38.730 & 0.9979 & 0.594 \\
\hline
\end{tabular}

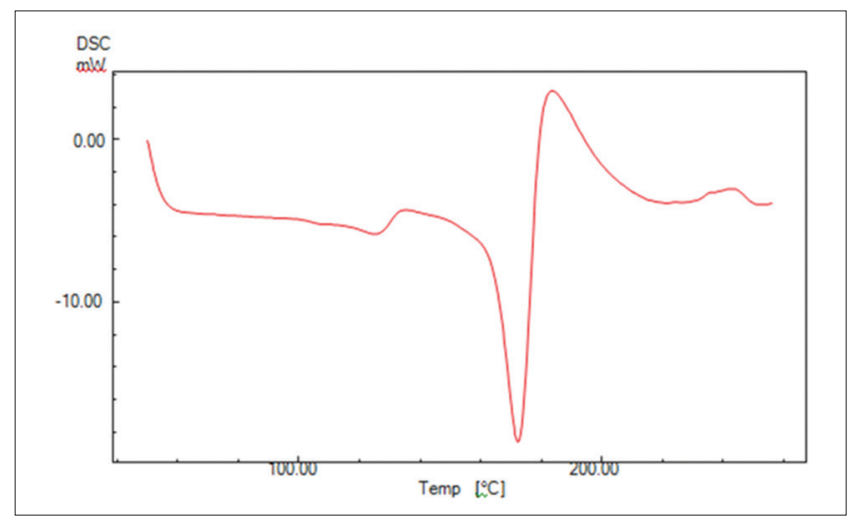

Fig. 12: DSC thermogram of pure candesartan cilexetil

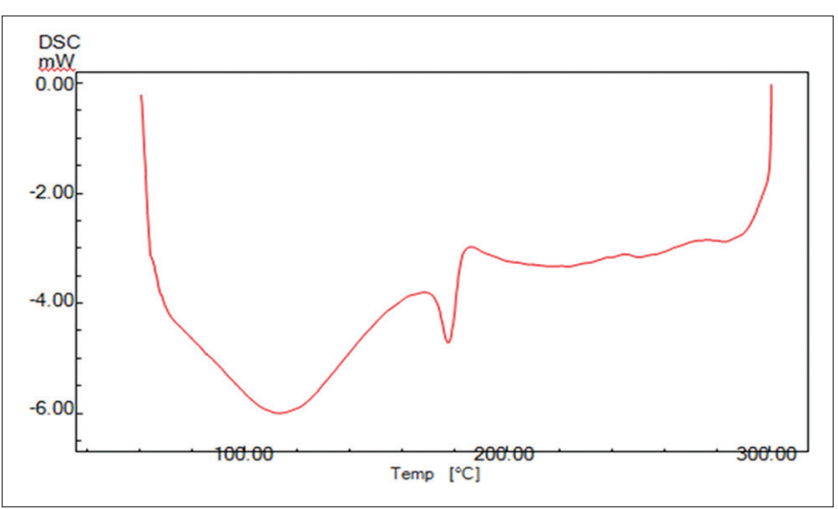

Fig. 13: DSC thermogram of candesartan cilexetil and HPMC K100M physical mixture (1:1)

The $\mathrm{pH}$ of the dissolution media affects the release of candesartan cilexetil from HPMC matrix system in spite of the polymer hydration and gelling not affected by change in the $\mathrm{pH}$ of the medium. The higher binding capacity of HPMC K100M to drug leads to more sustained effect than other polymers [25].

The hydrophilicity of acacia gum made the matrix system of the tablet releases the drug in a gradient manner in short time than other polymers. Acacia had gel forming mechanism in which it swells rapidly in contact with gastric fluid and maintains the shape integrity and bulk density less than the gastric content [26].

Eudragit RS 100 was in granular form and it used more widely than any other polymers, in which it is $\mathrm{pH}$-independent swelling polymer with good mucoadhesive properties [26]. Eudragit RS 100 sustains the release of candesartan cilexetil from the matrix system by floating mechanism.

Fast release $(100 \%$ in $5 \mathrm{hrs})$ was obtained from matrix tablets containing NaCMC polymer. High aqueous solubility and hygroscopic nature of NaCMC lead to rapid drug dissolution, diffusion, and relatively fast erosion of matrix systems, and this is because of the presence of ionized carboxylic acid groups in the polymer structure. These ionized carboxylic acid groups lead to an increase in the rate and amount of water uptake by ion-pair repulsion mechanism. Break of the bonds was responsible for the gel structure is due to stretch in the gel network [27].

The disordered random coil conformation of xanthan gum polymer loses its ability to form a gel structure while the ordered elongated conformation is able to form gel structure. The formation of an ordered structure in xanthan gum polymer will increase with increasing concentration of added salt. The presence of salt in the medium will cause the transition temperature $\left(\mathrm{T}_{\mathrm{m}}\right)$ to increase. In addition, the hydrodynamic volume of this polymer will change with changing in the ionic strength due to changes in the intramolecular electrostatic repulsion by the ions. Furthermore, the viscosity of xanthan gum affected by the ionic strength of the medium. All these properties will reflect the viscosity and gelation properties of the polymer and so affect the release time of the drug from the matrix system [14].

Tragacanth gum forms a weak gel once dissolved in water. The quality of crosslinking of the polymer is not as high as the chemical crosslinking. This property may be used for drugs having controlled release properties. The release mechanism from the matrix system of tragacanth polymer is by gelling of the polymer by water or buffer solution this will lead to form a less porous structure so tend the drug to will release [28].

IR study showed that presence of undisturbed candesartan cilexetil in the tablet. The IR spectra of the drug solubilized in various excipients were similar to that of the pure drug chromatograms, so there were no drug-excipients interactions as shown in Fig. 15 [29]. The data obtained from a dissolution study of the formulations were analyzed using various mathematical models as reported in DDSolver which is a specialized, freely available software program developed by Zhang et al. to provide a tool for facilitating the parameter calculations in dissolution data analysis using nonlinear optimization modeldependent approaches [30].

The highest correlation coefficient $\left(\mathrm{R}^{2}\right)$ was resulted with KorsmeyerPeppas model combined with zero order in case of F1, F7, and F10, which indicates that the drug release is ruled by both diffusions of the drug and dissolution/erosion of the tablet matrix. While F4, F13, and F16, the highest correlation coefficient $\left(\mathrm{R}^{2}\right)$ was resulted with KorsmeyerPeppas model combined with Higuchi model. Korsmeyer-Peppas model showed that the drug release kinetics is the most fitting because the values of the diffusion exponent (n) were between 0.484 and 1.039 The formulations (F1, F4, F7, F10, F13, and F16) were followed nonFickian diffusion kinetics, in which the diffusion exponent (n) values were $>0.5$. These results indicate that the release mechanism of the drug was shifted from diffusion controlled to an anomalous transport (non-Fickian), in which both the diffusion and the erosion mechanisms were controlling the release [12,31]. 


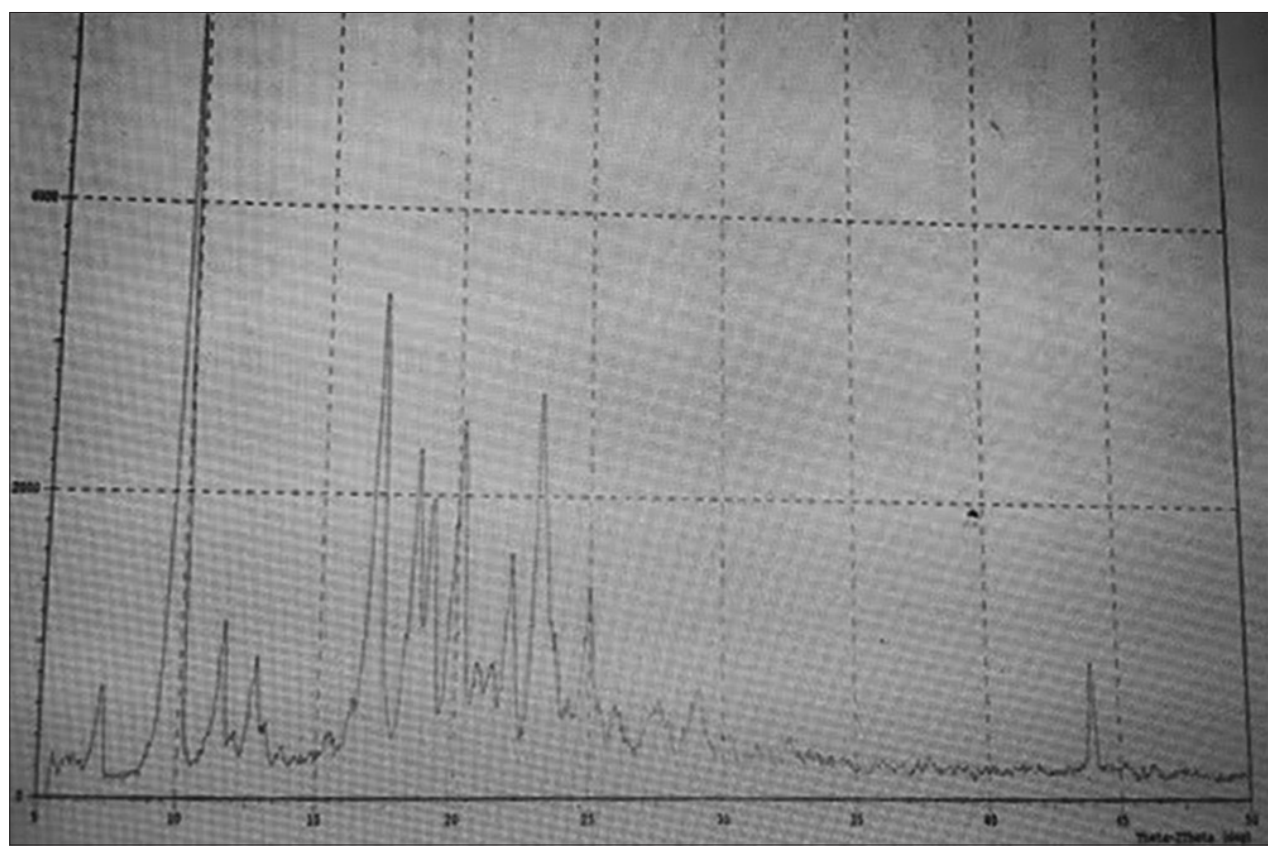

Fig. 14: X-Ray diffraction of pure candesartan cilexetil

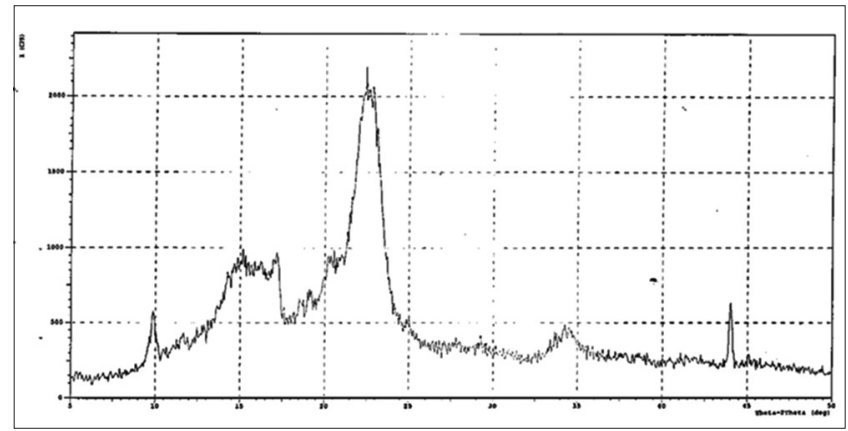

Fig. 15: X-Ray diffraction of candesartan cilexetil and HPMC K100M physical mixture (1:1)

\section{CONCLUSION}

Matrix tablet dosage form is one of the promising drug delivery systems for controlling the release of drug and to decrease the frequency of administration. F7 which contains HPMC K100M showed most sustain release for candesartan cilexetil than other studied polymers due to the higher binding and swelling of the polymer. HPMC K100M is hydrophilic polymer which absorbs water from dissolution media more than other polymers so, F7 can be used for sustain oral drug delivery of candesartan cilexetil. F13 in contrary which contains acacia gum showed faster release of the drug due to lower gelation than other polymers so F13 can be used as fast release tablets for faster response.

Controlled drug delivery system is promising for less dosing and higher patient compliance. Dry granulation method is good approach for enhancing flowability of poorly flowable powders and give other benefit which is enhance the binding of the tablet excipients and so higher harness will obtained than direct compression method.

\section{ACKNOWLEDGMENT}

Author is thankful to Micro labs, for providing me with the gift sample of candesartan cilexetil and author is also thankful to the Baghdad University, College of Pharmacy, for providing necessary infrastructure facilities required.

\section{REFERENCES}

1. Vishnu P, Naveen KB, Sunitha MR. Formulation and evaluation of candesartan cilexetil floating tablets by melt granulation technique. IJRPC 2015;5(2):373-9.

2. Al-Nuss R, El-Zein H. Enhancement of candesartan cilexetil dissolution rate by using different methods. Asian J Pharm Clin Res 2015;8(1): 320-6.

3. Dhrupesh P, Upendra P, Bhavin B, Dhiren D, Ghanshyam P. Formulation and evaluation of sustained release matrix tablets of candesartan cilexetil. IJPRBS, 2012;1(4): 75-101.

4. Bandyopadhyay S, Lohit B, Devi L. An explicit review on quantitative estimation of candesartan cilexetil employing various analytical techniques. Pharm Anal Acta 4:254. DOI: 10.4172/2153-2435.

5. Darphade SM, Shejul AA, Tathe PR, Biyani KR. Formulation and characterization of sustained release matrix tablet of metoprolol succinate by using combination of natural and synthetic polymer. Int $J$ Res Pharm Biomed Sci 2013;4(3):901-6.

6. Sasidhar RL, Vidyadhara, S, Krishna NR, Nagaraju R. Design and evaluation of losartan potassium matrix tablets with natural and synthetic polymers. Int J Pharm Sci Res 2012;3(3):928.

7. Chandramouli Y, Firoz S, Vikam A, Padmaja C, Chakravarthi VN. Design and evaluation of controlled release matrix tablets of acyclovir sodium using tamarind seed polysaccharides. J Pharm Biol 2012;2(2):55-62.

8. Shanmugam S, Baskaran R, Balakrishnan P, Thapa P, Yong CS, Yoo BK. Granulation techniques and technologies: Recent progresses. Bio Impacts 2015;5(1):55.

9. Kondeti RR, Mulpuri KS, Koganti M, Rathnam G. A comparative study on different methods of granulation on tablet properties. Asian J Pharm Technol Innov 2014, 2(7).

10. Basak SC, Kesevan SK, Murugesan R. Design and release characteristics of sustained release tablet containing metformin HCl. Rev Bras Ciên Farm 2008;44(3):477-83

11. Bhowmik A, Nijhu RS, Ahmed T, Sultana S. Design and development of atenolol matrix tablet employing natural and synthetic polymers. J Appl Pharm Sci 2013;3(9):13.

12. Girish B, Ismail P, Gowda D. Formulation and evaluation of sustained release matrix tablets of flurbiprofen using guar gum. Int J Pharm Pharm Sci 2012;4:120-3.

13. Abbas AA, Rasool A, Nawal AR. Preparation and comparative evaluation of liquisolid compact and solid dispersion of candesartan cilexetil. Int J Pharm Pharm Sci 2014;6 Suppl 2:257-66.

14. Salih OS. Study the sustain release effect of different polymers used in the formulation of aspirin-rosuvastatin tablets. Int J Pharm Pharm Sci 2015;7(12):166-72. 
15. Ofori-Kwakye K, Mfoafo KA, Kipo SL, Kuntworbe N, El-BoakyeGyasi M. Development and evaluation of natural gum-based extended release matrix tablets of two model drugs of different water solubilities by direct compression. Saudi Pharm J 2016;24(1):82-91.

16. Arora G, Malik K, Singh I, Arora S, Rana V. Formulation and evaluation of controlled release matrix mucoadhesive tablets of domperidone using Salvia plebeian gum. J Adv Pharm Technol Res 2011;2(3):163-9.

17. Shah RB, Mobin AT, Mansoor AK. Comparative evaluation of flow for pharmaceutical powders and granules. AAPS PharmSciTech 2008;9(1):250-8

18. Aulton, M. E. Pharmaceutics: The Science of Dosage form Design $1^{\text {st }}$ ed. London: Churchill Livingstone; 1998

19. Talukdar. MM, Kinget R. Comparative study on xanthan gum and hydroxypropylmethyl cellulose as matrices for controlled-release drug delivery. II. Drug diffusion in hydrated matrices. Int J Pharm 1997; 151:99-107.

20. Ghafourian T, Bozorgi AH. Estimation of drug solubility in water, PEG 400 and their binary mixtures using the molecular structures of solutes. Eur J Pharm Sci 2010;40(5):430-40.

21. Revathi T, Ethiraj Z, Jhansi L, Marreddy S, Ganeshan V. Development and validation of a dissolution test for candesartan cilexetil in table forms using reverse phase - High performance liquid chromatography. J Pharm Educ Res 2011;2:22-36.

22. Shukla JB, Patel SJ. Formulation and evaluation of selfmicroemulsifying system of candesartan cilexetin. Int J Pharm Pharm Sci 2010;2(4):143-6.

23. Sinko PJ, Alfred NM. Physical chemical and biopharmaceutical principles in the pharmaceutical sciences. Martin's Physical Pharmacy and Pharmaceutical Sciences. Solubility and Distribution Phenomena. $6^{\text {th }}$ ed. Lippincott: Williams \& Wilkins; 2011. p. 184

24. Albhar KG, Vaibhav SW, Chavan BB. Effect of HPMC K4M, HPMC $\mathrm{K} 15 \mathrm{M}$, sodium alginate and carbopol 934 in the formulation of carbonyl iron capsule. J Der Pharm Lett 2012;4(1):94-367.

25. Roy H, Chandan KB, Sisir N, Kirti RP. Formulation and design of sustained release matrix tablets of metformin hydrochloride: Influence of hypromellose and polyacrylate polymers. Int J Appl Basic Med Res 2013;3(1):55.

26. Kaushik AY, Ajay KT, Ajay G. Role of excipients and polymeric advancements in preparation of floating drug delivery systems. Int $\mathrm{J}$ Pharm Invest 2015;5(1):1-12.

27. Palmer D, Levina M, Nokhodchi A, Douroumis D, Farrell T, RajabiSiahboomi A. The influence of sodium carboxymethylcellulose on drug release from polyethylene oxide extended release matrices. AAPS PharmSciTech 2011;12(3):862-71.

28. Kaffashi B, Zandieh A, Khadiv-Parsi P. Drug release study of systems containing the tragacanth and collagen composite: Release characterization and viscoelastic measurements. Macromol symp 2006;76(1):230-239.

29. Reddy PU, Reddy BV, Navaneetha K. Formulation and evaluation of candesartan immediate release tablets by using liquisolid. World J Pharm Pharm Sci 2013;3(2):2270-82.

30. Zhang Y, Huo M, Zhou J, Zou A, Li W, Yao C, et al. DDSolver: An addin program for modeling and comparison of drug dissolution profiles. AAPS J 2010;12:263-71.

31. Naseera K, Sajeeth CI, Santhi K. Formulation, optimization and evaluation of matrix type of transdermal system of simvastatin using permeation enhancers. Int J Curr Pharm Res 2012;4(2):79-87. 